\title{
GLAD!
}

Revue sur le langage, le genre, les sexualités

$02 \mid 2017$

Varia

\section{Le matérialisme discursif. Pour une critique féministe de la construction idéologique du « sexe»}

Résumé de thèse

Discursive Materialism. A Feminist Critique of the Ideological Construction of

"Sex"

\section{Audrey Benoit}

\section{OpenEdition}

\section{Journals}

Édition électronique

URL : http://journals.openedition.org/glad/528

DOI : $10.4000 /$ glad.528

ISSN : 2551-0819

\section{Éditeur}

Association GSL

\section{Référence électronique}

Audrey Benoit, « Le matérialisme discursif. Pour une critique féministe de la construction idéologique du " sexe » », GLAD! [En ligne], 02 | 2017, mis en ligne le 01 juin 2017, consulté le 21 janvier 2021. URL: http://journals.openedition.org/glad/528 ; DOI : https://doi.org/10.4000/glad.528

Ce document a été généré automatiquement le 21 janvier 2021.

\section{(c) (i) $(9)$}

La revue GLAD! est mise à disposition selon les termes de la Licence Creative Commons Attribution Pas d'Utilisation Commerciale - Pas de Modification 4.0 International. 


\section{Le matérialisme discursif. Pour une critique féministe de la construction idéologique du "sexe "}

Résumé de thèse

Discursive Materialism. A Feminist Critique of the Ideological Construction of

"Sex"

Audrey Benoit

\section{RÉFÉRENCE}

A. Benoit. 2016. Le matérialisme discursif. Pour une critique féministe de la construction idéologique du « sexe ». Thèse de doctorat en Philosophie, sous la direction de Bertrand Binoche, Université Paris 1 Panthéon-Sorbonne.

1 Le point de départ du travail est un constat: la thèse féministe, que Judith Butler défend en 1990 dans Trouble dans le genre, selon laquelle la catégorie de «sexe »ne décrit pas la réalité naturelle de la différence de l'homme et de la femme, mais relève d'une construction discursive produite par les normes hétérosexistes du genre, a rencontré d'importantes résistances théoriques, jusque dans certains cercles féministes et/ou matérialistes. Le parti pris qui est celui de Butler en 1990, d'intégrer la critique féministe à un combat plus large contre le pouvoir des normes d'une hétérosexualité dominante, confère à sa position toute sa portée mais aussi tout son danger pour ses détracteurs : en ébranlant le présupposé selon lequel la différence sexuelle, au nom de son inscription biologique dans la matérialité des corps, relèverait d'un fait antérieur au discours - ce qui rend ce prétendu fait aussi in-interrogeable qu'incontestable Butler fait vaciller le positivisme naturaliste qui sous-tend l'acceptation sociale d'un vaste spectre d'oppressions juridiques, politiques, économiques et symboliques, qui touchent aussi bien les femmes que les personnes homosexuelles. S'attaquant aux fondements épistémologiques de l'hétérosexisme, Butler touche au dernier rempart de 
l'empirisme naïf: le caractère irréfutable de la réalité matérielle du corps, en tant qu'hétérosexué. Sa thèse se trouve alors contestée sur deux fronts : outre qu'on lui reproche universellement de nier la matérialité du corps, on lui reproche plus particulièrement, chez les matérialistes, de négliger la réalité économique matérielle qui détermine les rapports sociaux, au profit d'une réflexion idéaliste sur le langage. Or ces deux critiques trahissent une même conception empiriste de la matière, que le travail de recherche entreprend de mettre en question, de l'intérieur de la tradition matérialiste.

2 Le travail envisage d'abord les critiques adressées à Butler au sein du champ féministe, en étudiant l'étonnante convergence de la critique post-marxiste de Christine Delphy et de celle de Nancy Fraser, conduite depuis le champ de la théorie critique. Toutes deux ont en commun de s'appuyer sur une très nette partition des aspects matériels et discursifs de l'existence sociale, renvoyant à une même conception réductionniste de la matérialité sociale. Il en résulte un antagonisme apparent entre une perspective matérialiste, susceptible de mettre au jour le conditionnement économique des rapports sociaux de sexe, et une perspective constructiviste qui se contenterait de révéler le pouvoir du discours sur le plan des représentations culturelles. Or la thèse butlerienne gagne à être envisagée d'un point de vue matérialiste. Son horizon est d'intégrer la question de la régulation discursive des normes du genre à celle de la reproduction du mode de production capitaliste.

3 Pour répondre à ce problème, la majeure partie de la recherche est donc consacrée à l'exploration, en amont dans l'histoire de la philosophie, d'une voie matérialiste pour penser la construction conceptuelle du donné par le discours. La conjonction originale proposée par Althusser entre l'épistémologie historique et le marxisme offre une telle possibilité: le discours n'est plus le simple reflet d'un dehors, ni le relais de déterminations extérieures, mais l'espace de production des objets de la connaissance. En remontant à la source de Marx, on peut en effet montrer que sa pensée a nourri chez Althusser une approche matérialiste du discours très particulière, dont on retrouve des accents dans l'archéologie foucaldienne. Il s'agit d'un matérialisme discursif, ayant pour caractéristique de faire du discours le mode de donation théorique des objets et le milieu d'existence matérielle de l'idéologie. Au prisme de l'épistémologie historique de Canguilhem, se dessinent des parentés entre Althusser et Foucault qui donnent une postérité inédite à Marx : le matérialisme discursif althussérien permet notamment de rendre caduques les objections empiristes à l'idée d'une construction discursive du "sexe ». On cherche ainsi à proposer des éléments pour une articulation du matérialisme marxiste et de la pensée queer, afin d'envisager la construction du donné d'un point de vue matérialiste et de prendre au sérieux la production de la nature et du corps par le discours. Il s'agit par là de donner à la thèse de Judith Butler les conditions de son audibilité matérialiste, et de déterminer en retour la fécondité de sa mise en question du donné pour le marxisme. 
INDEX

Keywords : feminism, materialism, discourse, sex, gender, ideology, marxism, Historical Epistemology, Judith Butler, Louis Althusser, Michel Foucault, Karl Marx, Georges Canguilhem Mots-clés : féminisme, matérialisme, discours, sexe, genre, idéologie, marxisme, épistémologie historique, Judith Butler, Louis Althusser, Michel Foucault, Karl Marx, Georges Canguilhem

Thèmes : Actualités 